\title{
The Value of Ethnic Diversity in the Teaching Profession: A New Zealand Case Study
}

\author{
Jocelyn Howard \\ School of Māori, Social and Cultural Studies, College of Education \\ University of Canterbury \\ Private Bag 4800, Christchurch 8140, New Zealand \\ Tel: 0064-3-345-8247Ｅ-mail: jocelyn.howard@canterbury.ac.nz
}

\begin{abstract}
Changing demographics in many contemporary Western countries have resulted in multiethnic societies with teaching workforces that have not kept pace with the increased diversity of student populations. International research indicates that teachers from minority language and cultural backgrounds can impact positively on minority students' self-esteem and academic performance, and that all students can benefit from a diverse teaching workforce. This paper reviews the literature on race-matched teaching and the impact of diversity in the teaching profession, and then reports on a case study which explores these issues specifically in the New Zealand context. The generation 1.5 Asian New Zealand and third-generation Anglo-European New Zealand student participants and their parents reported both challenges and benefits associated with strictly race- or ethnicity-matched teacher assignment and also with increased teacher diversity. Participants also highlighted the need for all teachers to be trained to work effectively with diverse student populations. The paper concludes by discussing the role of teacher education programmes in developing a culturally responsive teaching workforce for a future New Zealand where minority ethnicity students will outnumber the present Anglo-European majority. This paper has relevance for many other educational contexts with large multiracial, multiethnic populations.
\end{abstract}

Keywords: Cultural diversity, Ethnic diversity, Race-matched teaching, Culturally responsive teaching, Multicultural teacher education, Equity in education 


\section{Introduction}

Dramatic changes have occurred in the racial and ethnic composition of New Zealand's population as the immigration policies and quotas of the 1980s have been progressively relaxed. These demographic changes are reflected in an increasingly diverse student population. Māori and Pasifika students, who traditionally constituted the largest groups of non-Anglo-European ancestry students in many schools, have now been joined by students from over one hundred different language and cultural backgrounds. More than $40 \%$ of domestic students in New Zealand schools are now from non-Anglo-European backgrounds, and the age structure of the existing population, migration projections, and the higher than national average Māori and Pasifika fertility rates indicate that minority-ethnicity (Note 1) student numbers will continue to increase (Ministry of Education [MOE], 2007; Statistics New Zealand, 2007; Statistics New Zealand, 2010). Similar demographic changes have also been noted in other Western countries.

While the New Zealand student population has become increasingly diverse, the ethnic composition of the teaching workforce has remained relatively static. At least $79 \%$ of primary and secondary school teachers in the most recent New Zealand teacher census were of Anglo-European ancestry (MOE, 2005). Although the proportion of beginning teachers from minority backgrounds is now higher than for the total teaching population ( $3 \%$ versus $2 \%$ ), continuing high attrition rates for beginning teachers (40\% within four years) indicate that significant ethnic changes in teaching demographics are unlikely in the medium term (MOE, 2006a).

Concern about ethnic disparity in student and teacher numbers has raised questions about the need for a more representative teaching population in a number of countries, and has also spurred debate about the place of race-matched teaching. Reports covering a wide range of sectors indicate that an ethnically diverse workforce confers benefits at individual, institutional, and national levels (Milem, 2003). Researchers suggest "there is good reason to believe that similar benefits apply to students, teachers, and schools as well" (Torres, Santos, Peck, \& Cortes, 2004, p. 4). Some writers argue that a teaching workforce that reflects the ethnic composition of the society it serves is of vital importance in preparing all students for the future (see, for example, Chaika, 2005; Kane \& Orsini, 2003; Tyler, Yzquierdo, Lopez-Reyna, \& Flippen, 2004). Other reports focus on demographic disparities in achievement and retention rates, and suggest that an ethnically representative teaching faculty is especially important for minority students (Beynon, Toohey, \& Kishor, 1998; Ford, Grantham, \& Harris, 1997; Miller \& Endo, 2005). The Carnegie Taskforce on Teaching as a Profession (1986) puts it this way:

Schools form children's opinions about the larger society and their own futures. The race and background of their teachers tells them something about authority and power .... These messages influence children's attitudes toward school, their academic accomplishments, and their views of their own and others' intrinsic worth. (p. 79)

This paper reviews the rationale for race-matched teaching and for a more diverse teaching 
population. It then reports the findings of a case study that examined the views of generation 1.5 Asian New Zealand students, third-generation Anglo-European New Zealand students, and parents of both groups in relation to race-matched teaching and the implications and outcomes of a more ethnically diverse teaching workforce.

\section{Background}

\subsection{Race-matched teaching}

Calls for a more diverse teaching workforce in New Zealand are commonly rooted in concerns for social justice, and disquiet at the disproportionate underachievement of Māori and Pasifika students in national education statistics (Telford \& Caygill, 2007). Similar concerns about the under-representation of minorities in the teaching profession in Australia also give prominence to the indigenous population (Hartsuyker, 2007). Some educators believe these minority students will perform better with own-race teachers, and similar ideas are mooted in relation to generation 1.5 students. A body of research offers support for these claims.

For example, American studies of teacher behaviour indicate that minority students' race or ethnicity can negatively influence teachers' initial judgements of their academic potential (Ehrenberg, Goldhaber \& Brewer, 1995; Ferguson, 1998; Neal, McCray, Webb-Johnson, \& Bridges, 2003). Research also indicates that race biases teachers' interactions with students, and affects both the quantity of teacher time and the amount of positive reinforcement that minority students receive (Casteel, 1998). Other American studies suggest that the disproportionate placement of minority students in special education programmes and their under-representation in programmes for gifted and talented students may be the result of cultural differences that are misinterpreted by teachers of the dominant ethnicity (Bennett, 2003; Ford et al., 1997). Kane and Orsini (2003) suggest that such "evidence of teachers' differential attitudes and behaviours based on race shows that teachers of color are a needed presence in all schools to help their White colleagues question their attitudes and reflect on their behaviour toward students" (p. 15).

Studies in New Zealand echo American findings that many mainstream teachers have lower expectations of some minority students (Alton-Lee, 2003). Bishop, Berryman, Powell, and Teddy (2007) report that New Zealand teachers frequently explain low levels of Māori achievement in terms of the students' own deficiencies. The researchers claim that "such deficit theorising ... creates self-fulfilling prophesies of failure" (p. 5), which in turn feed a diminishing sense of agency in relation to these students on the part of many majority-culture teachers. The similarities in the findings from many New Zealand, Australian and American studies suggest that Nieto (1999) could be referring to classrooms in many countries with majority Anglo-European populations when she states:

... cultural, linguistic and other differences are commonly viewed as temporary, if troublesome, barriers to learning. Consequently, students of diverse backgrounds are treated as walking sets of deficiencies, as if they had nothing to bring to the educational enterprise. (p. 34) 
Perhaps the most commonly cited benefit for race-matched teaching is that minority teachers provide vital role models for minority students and signal important messages about their self worth (Ford et al., 1997; Gordon, 2002; Kane \& Orsini, 2003; Ladson-Billings, 1994; Miller \& Endo, 2005), thereby enabling minority students to "envision themselves as key players and future professionals in schools" (Beynon et al., 1998, p. 64). Dee (2005) refers to these role-model effects as "passive" effects, occurring when "the presence of a demographically similar teacher raises a student's academic motivation and expectations" (p. 3). Recent New Zealand teacher recruitment material presupposes a similar phenomenon when it emphasises that "young Māori need Māori role models to teach and guide them", and that Māori teachers "help to ... raise expectations leading to higher educational achievement for Māori" (TeachNZ, 2007, p. 1).

Kennedy (1991) offers a more in-depth description of this process:

Teachers do much more than literally teach content. They also personify content. They stand as models for what it is like to be an educated person ... If we want students to believe that they themselves might one day be ... mentors, guides, and educated people, then we need them to see diverse examples of such people, including at least one who looks like they, the students, look. (p. 660)

Nakeela Wright, a 24-year-old participant in the Teacher of Color Development Program in Minnesota, reinforces this message, when she describes the impact of minority teachers from a personal perspective:

When children are younger and if there are people of color in the classroom, they can say, "Whoa, this is a person just like me". ... Sometimes seeing someone up there that looks just like you or similar to you is powerful. It's a very deep image and it can go a long way. (Cited in Barbieri, 1998, p. B1)

American research indicates that minority teachers also help minority students adjust to the "lack of synchrony between home and school culture" (Genzuk, 1997, p. 2). They act, directly and indirectly, as "cultural translators" (Ford et al., 1997, p. 214), helping minority students to make connections between their own backgrounds and school systems, which are commonly founded on the values and norms of the dominant culture.

Miller and Endo (2005) and Nieto (1999), among others, claim minority students also feel more comfortable with own-race teachers; that they can make it easier for minority students to seek assistance, and help students to feel their first-culture identities and values are appreciated and respected during critical periods of acculturation. As one minority student explains, minority students need adults in their schools who "understand the complexities of our lives and the adjustments that we need to make in order to fit in" (cited in Brosnan, 2002, p. 12); "someone," as university minority recruitment director Evelyn Dandy says, "who listens to the same music, enjoys the same foods, laughs at the same jokes, cries about the same problems, [and] worships the same way" (cited in Chaika, 2005, p. 1). Australia's Committee for the Review of Teaching and Teacher Education [CRTTE] (2003) supports such claims when it calls for greater numbers of indigenous teachers: "Such teachers ... bring 
a capacity for closer rapport and identification with students from Indigenous backgrounds" (p. 21).

For minority students with limited English proficiency, same-race teachers can provide valuable language support within the school setting and assistance in making connections between school and homes with non-English-speaking parents (Chinn \& Wong, 1992; Peng \& Wright, 1994). They can also be instrumental in minority students' first-language maintenance through the development of bilingual programmes and by creating a classroom culture that allows for and affirms first language use. In many schools, own-race teachers also serve as advocates and mediators for minority students in a wide range of situations.

Some commentators (such as Ford et al., 1997; Stokes, 1999) hypothesise that in addition to benefiting the affective wellbeing of minority students, a diverse teaching faculty can also impact positively on minority students' academic achievements. The empirical evidence that exists on the impact of race-matched teaching on educational performance provides conflicting results, though. Ehrenberg et al.'s (1995) examination of possible links between teacher-student race and student achievement failed to prove a strong association between own-race teachers and student outcomes. However, Dee's (2001) analysis of existing test score data from 11,600 students provided "consistent evidence that there are rather large educational benefits for both black and white students from assignment to an own-race teacher" (p. 22). Reports also indicate that minority students' test results are positively affected when tests are administered by own-race personnel (LaPlante \& Carlson, 1996; Sianjina, Cage, \& Allen, 1996).

There is little literature specifically related to the benefits of race-matched teaching for Asian minority students, although it is hypothesised that many of the benefits reported above apply across all minority groups. However, a study by Gordon (2000b) that examined interview data from over 200 Latino, African American, Native American, and Asian American teachers and educational professionals found Asian Americans viewed race-matched teaching differently to the other three minority groups. Gordon reports that while the former three groups perceived advantages in recruiting minority teachers to work in schools with a high proportion of same-race students, most Asian American participants believed "race-matched teaching was not of significance" (p. ix). The majority of Gordon's Asian-ancestry informants cited initial language assistance as children transitioned into their new schools as the only potential justification for race- or ethnicity-based teacher assignment (2000b, p.76).

\subsection{The wider impact of a diverse teaching force}

A number of studies report that in addition to providing advantages for minority students, an ethnically diverse teaching population contributes beneficially to the education of all students (Chaika, 2005; Futrell, 1999; Gursky, 2002; Miller \& Endo, 2005). Dr Airini, associate dean of the Education Faculty at the University of Auckland, New Zealand, acknowledged the importance of minority teachers as role models for majority as well as minority students when she referred to graduating Pasifika early childhood education teachers "as 'Pacific Pearls', because they are considered so valuable to both our Pasifika and mainstream communities" ("Pacific Pearls", 2007). 
Literature in this field also gives prominence to the influential role a multiethnic teaching force plays in reducing racial and cultural intolerance (Kane \& Orsini, 2003; Lee, 1991). Recent New Zealand reports reinforce international articles which indicate that a high degree of racial prejudice exists in many schools and communities, and that for a large number of minority students, race-based harassment and bullying are common occurrences (Chang, Morris, \& Vokes, 2006; Gordon, Mutch, Howard, Heazlewood, Coleman, \& Hendren, 2006). Researchers maintain that alongside supportive policy and practice at an administration level, student engagement with culturally diverse teachers is instrumental in developing a school-wide culture that is more tolerant of different races and ethnicities (Beynon et al., 1998; Gordon, 2002). Denise Littleton, director of the Pathways to Teaching Careers programme at Norfolk State University, explains:

It's helpful for students to see someone similar to them as a teacher, and it's also helpful for the non-minority students. We live in a diverse society. We need to know how to get along with people from diverse cultures and backgrounds. (Cited in Rasmussen, 1999, pp. 1-2)

The role of a diverse teaching faculty in preparing students to function positively and effectively in increasingly multicultural societies is also stressed by other researchers (Gagliardi, 1995; Rong \& Preissle, 1997). Some writers highlight the need for all students to develop intercultural communication skills in preparation for a future where people of Anglo-European ancestry will increasingly constitute a minority in many societies (Kane \& Orsini, 2003; Tyler et al., 2004). Economic imperatives resulting from rapidly globalised market places are also given as the rationale for equipping students with the ability to relate to others from different racial and linguistic backgrounds (Chaika, 2005).

Vegas, Murnane, and Willett (2001) emphasise the need for all children "to observe that adults from different ethnic backgrounds can effectively hold leadership positions in our society" (pp. 1-2). Other researchers also suggest that such exposure to minority adults in positions of authority as teachers and educational administrators plays an important part in breaking down stereotypical views of employment roles, thereby conferring benefits on both minority and dominant culture students and adults (Villegas \& Clewell, 1998).

A multiethnic teaching population can also benefit the wider student body by increasing their exposure to a greater range of experiences and "infus[ing] a broader range of cultural perspectives into schools" (CRTTE, 2003, p. 21). As Armstrong and Savage (2002) explain:

If you are a member of the white majority, you may well live in a world where perspectives of your own group are so dominant that you may fail to recognize that you have a worldview that may differ from that of members of other cultural and ethnic groups. (p. 172)

Kane and Orsini (2003) speculate that such exposure to new ways of seeing things is perhaps especially important in institutions that are "steeped in White, upper-middle-class traditions of culture and education" (p. 12), and that the different pedagogical models and alternative classroom management approaches may prove valuable not just to students, but also to 
dominant-culture teaching colleagues. In this context it is claimed that an ethnically diverse teaching population can help to reduce individual and institutional racism by creating a more culturally informed workforce and contributing to a pedagogy and curriculum that has greater cultural relevance for all students ( $\mathrm{Su}, 1996)$.

\section{Case Study}

\subsection{Method}

This exploratory study utilised a qualitative case study approach to investigate the following overarching research questions:

How do generation 1.5 Asian New Zealand students and their parents perceive race-matched teaching?

Do generation 1.5 Asian New Zealand students and their parents perceive a need for a more ethnically diverse teaching workforce?

Do Anglo-European New Zealanders perceive benefits in having a more ethnically diverse teaching population?

A self-completion survey and focus group interviews were employed to explore the perspectives of three groups of high school students and their parents in relation to the research questions. Bogdan and Biklen (1992) and Burns (2000) confirm the strength of case study methodology for this type of investigation and advocate the use of multiple-data subjects and sources so that comparisons can be made between individual cases, as well as to facilitate triangulation of the findings. However, it must be stressed that readers need to exercise appropriate caution when assessing the degree and extent to which the case study findings are transferable to other contexts.

\subsection{Participants}

The student participants in this study comprised four generation 1.5 Chinese New Zealanders, five generation 1.5 South Korean New Zealanders, and six students of Anglo-European ancestry who were at least third generation New Zealanders. All students were aged between 16 and 18, and were in their final two years of study at the same urban New Zealand Decile 7 high school. The students of Asian ancestry had lived in New Zealand for between two and 12 years, and all Anglo-European New Zealand students were born and educated in New Zealand. Purposive convenience sampling (Merriam, 1998) was used to select the student participants, with assistance from staff at the school to ensure all participants' English language proficiency was sufficient for them to undertake the interviews confidently in English.

Ten of the students' parents consented to take part in the study; five Chinese New Zealanders, two South Korean New Zealanders, and three parents of Anglo-European ancestry who were at least fourth generation New Zealanders. Parent participants were between 40 and 53 years of age. Those of Asian ancestry had lived in New Zealand for between three and 11 years. 


\subsection{Data collection tools and procedures}

\subsubsection{Students}

All student participants in the study were informed of the nature and purpose of the study orally at an early briefing session, and were also given a preliminary information sheet in their first languages to ensure they understood the requirements and expectations fully before consenting to take part. They then received a short questionnaire eliciting demographic information and an interview schedule which included questions from an earlier study by Gordon (2000a). Participants were invited to write notes in response to these interview questions prior to focus group discussions, and these were included in the data analysis.

Focus group interviews were selected as the primary research instrument for this stage of the study because they provided opportunities for the participants to interact with, and react to, one another, and for the researcher to probe, where appropriate, to gain a deeper understanding of the reasoning behind some of the responses (Burns, 2000; Vaughn, Schumm, $\&$ Sinagub, 1996). The three focus groups were arranged by ethnicity, with a maximum of six students in each to allow sufficient time for all participants to share their opinions and experiences. The interviews, conducted in English, each took approximately 60 minutes. These were recorded and were later fully transcribed for analysis. At the conclusion of each discussion, the students were given a summary of their comments and offered the opportunity to listen to the recordings so they could make additions or changes. Each student was compensated for his or her participation with a book or movie voucher.

\subsubsection{Parents}

Parent participants received an explanatory letter about the study along with a consent form and a self-completion questionnaire. These were written both in English and in the parent participants' first languages, and were delivered home by student participants following the focus group interviews, along with stamped addressed envelopes for their return. The questionnaires contained open and closed questions designed to gather baseline demographic information as well as qualitative responses. All questionnaires that were completed in the parent respondents' first languages were later professionally translated prior to analysis.

\subsection{Data analysis}

Data from the focus group interviews and from the qualitative component of the parents' surveys were analysed using a cyclic constant comparative approach to identify and categorise emerging themes and dissonances (Davidson \& Tollich, 2003; Kreuger \& Casey, 2000). The data were examined firstly for each group separately and then across all groups in order to explore any differences in the perceptions of each of the Asian New Zealand groups, and to identify possible differences between the Asian New Zealand and majority ethnicity participants.

Extracts from the focus group interviews and the questionnaire responses are included in the following presentation of findings to support the researcher's interpretation of the data, and also to illustrate complexities and nuances within the issues being explored. 


\section{Results}

To determine the perceived advantages and disadvantages of race-matched teaching, participants of Asian ancestry were asked whether they thought it was important for South Korean/Chinese children in New Zealand schools to have South Korean/Chinese teachers. Although both parent and student groups outlined some potential advantages of having same-race teachers, they also drew attention to potential disadvantages. The majority of both groups indicated that they did not expect race-matched teaching in New Zealand, nor did they view it as necessary. One Chinese New Zealand student echoed the sentiments of many other Asian New Zealand participants when she said: "I reckon when you come here, you're not expecting [same-race] teachers to be teaching you because you are going to a western country" (CNZ Student 4).

Asian New Zealand parent and student participants expressed similar reservations in relation to having a more ethnically diverse teaching workforce, particularly if the teachers were from different ethnic backgrounds to their own. However, they also perceived a number of advantages - some for minority ethnicity students, some for majority culture students and some for New Zealand society as a whole.

All Anglo-European New Zealand parents in the study felt that Anglo-European heritage teachers were preferable to minority-ethnicity teachers. In contrast, the majority culture student group spoke very positively about personal and societal advantages that a diverse teaching profession might confer, although they also drew attention to some potential disadvantages.

Eleven of the themes that emerged during analysis of the questionnaire and focus group data have been categorised into those outcomes perceived to derive from race-matched teaching and those reported for a more diverse teaching workforce (see Table 1).

One further theme that emerged from the study related to the need for all teachers to be trained to work effectively with an ethnically diverse student population. Each of these themes is now reported individually.

\subsection{Perceived Outcomes of Race-matched Teaching}

\subsubsection{Role Modelling}

Participants in both Asian-heritage student groups indicated that Asian teachers could be valuable role models for same-race students. Both groups also proposed that this might influence minority students' career decisions: "It might encourage people to do teaching if they saw teachers from their own country" (CNZ Student 1).

\subsubsection{Increased Confidence}

Participants in all student groups suggested that same-race teachers may assist in making the school environment less alienating for minority-ethnicity students, thereby giving them a greater sense of self-esteem as they adjusted to life in their new country and negotiated between the different cultures. One Asian New Zealand parent agreed in relation to initial 
Table 1. Perceived outcomes of race-matched teaching and a diverse teaching population

\begin{tabular}{|c|c|}
\hline Race-matched teaching & More diverse teaching population \\
\hline Role modelling for minority students & Role modelling for minority students \\
\hline Increased confidence of minority students & Increased confidence of minority students \\
\hline Pastoral support for minority students & Pastoral support for minority students \\
\hline Reduced English language development & Reduced English language development \\
\hline \multirow[t]{7}{*}{ Stigmatisation of minority students } & Stigmatisation of minority students \\
\hline & $\begin{array}{l}\text { Exclusion of majority-culture and } \\
\text { other-culture students }\end{array}$ \\
\hline & $\begin{array}{l}\text { Challenges understanding minority } \\
\text { teachers }\end{array}$ \\
\hline & $\begin{array}{l}\text { Exposure to other teaching methods and } \\
\text { ideas }\end{array}$ \\
\hline & Increased cultural understanding \\
\hline & Reduced occupational stereotyping \\
\hline & Increased racial tolerance \\
\hline
\end{tabular}

race-matched placement: "at the beginning - this can give children confidence" (CNZ Parent 2).

\subsubsection{Pastoral Support}

Added assistance and pastoral support for minority students was the perceived benefit of race-matched teaching most commonly mentioned by the Asian and the Anglo-European New Zealand respondents. Participants commented that minority teachers "would probably make students with the same culture feel more comfortable" (ENZ Student 3), and, by having "a better understanding of the [minority] students' background" (SKNZ Student 2), same-race teachers would have a better sense of the type of support that was needed. Asian students and parents expressed concerns, however, that minority students could become too dependent on a same-race teacher and not develop the skills necessary for independence: "You can become too reliant, and maybe you won't be able to do those things yourself when you need to" (SKNZ Student 3). 


\subsubsection{Reduced English Language Development}

The ability of a same-race teacher to provide academic as well as pastoral support to students in their first language was another commonly mentioned outcome of race-matched teaching. Respondents' comments made it clear, however, that this was perceived to have both advantages and disadvantages. Almost all Asian parents expressed strong concerns that race-matched teaching could detract from their children's English language development, and indicated that "the English environment is more beneficial for children to get into society in New Zealand" (CNZ Parent 1). Most of the Asian students shared their parents concerns: "If you have a teacher who speaks your own language, you're not going to put the effort in to speak English" (CNZ Student 2). Similar concerns were expressed, albeit in different terms, by majority-culture students: “... [minority students] wouldn't get used to speaking the normal language" (ENZ Student 2). However, all student groups also recognised advantages in having a teacher who was fluent in a common language: "You would probably get help if you don't understand. If you are having trouble at school there would be someone to go to" (CNZ Student 2).

\subsubsection{Stigmatisation}

The possibility that race-matched teaching might draw unwelcome attention to their cultural dissimilarity concerned students in both Asian-heritage groups. These students also expressed concern about the potential for accusations by majority-culture students of minority students being favoured by same-race teachers: "As a result of that you could become outcast" (SKNZ Student 3).

\subsection{Perceived Outcomes of a More Diverse Teaching Population}

All five themes that emerged in relation to race-matched teaching were also perceived as potential outcomes for a more ethnically diverse teaching population. To reiterate, these were role modelling, increased confidence, pastoral support, reduced English language development and stigmatisation. A further six themes emerged for a more ethnically diverse teaching workforce.

\subsubsection{Exclusion of Other Students}

Majority-culture students expressed concern that they and other students who were not from the same first language background as a minority teacher could be excluded if the teacher favoured same-race students: "They could speak to them in the same language and nobody else would be able to understand it" (ENZ Student 1). The Anglo-European New Zealand students also expressed concern that they might not be able to engage fully in the class because of fears they could inadvertently offend a minority teacher: "We might say or do something by accident and not mean anything by it, but they could take it really personally" (ENZ Student 4).

\subsubsection{Challenges Understanding Minority Teachers}

Another prominent source of concern for Anglo-European heritage students was the potential difficulty they might have understanding a minority teacher's accent: "The language would 
be a real issue. You'd have to have them speaking good English" (ENZ Student 4). Asian-heritage students similarly suggested that they may be disadvantaged if they had to struggle to understand a minority-ethnicity teacher from a language background different to their own.

\subsubsection{Exposure to Other Teaching Methods and Ideas}

The majority of students in all three ethnic groups suggested that it could be beneficial for students to be exposed to the different teaching methods and ideas that a more diverse teaching community could bring: "If you have teachers that are all New Zealand European you are getting only that one sort of style and view" (ENZ Student 5). Some students expressed reservations, though: "Each teacher would bring their own beliefs, their own teaching styles, their own wisdom, but I'm not sure what effect that would have on the whole school ... It might not be so good" (ENZ Student 6). One Asian New Zealand student referred to specific teaching practices employed by some minority-ethnicity teachers, expressing concern that "students wouldn't understand the way they are teaching" (CNZ Student 3).

\subsubsection{Increased Cultural Understanding}

The majority of Asian parents were positive about the potential effect of longer-term exposure to teachers from different ethnic backgrounds. However, this was sometimes with particular reference to majority-culture students: "They can learn other country's good merits, they can compare different cultures, and they can become more open-minded in society" (SKNZ Parent 1). Anglo-European New Zealand students, themselves, also recognised ways in which minority ethnicity teachers could expand their cultural understanding: "They bring a different perspective which enhances your learning and enhances your views on life" (ENZ Student 5). In contrast, however, one Anglo-European heritage parent stressed the importance of teachers having an understanding of "the New Zealand lifestyle and the culture. People born here are more likely to have that understanding" (ENZ Parent 2).

\subsubsection{Reduced Occupational Stereotyping}

Minority and majority culture students suggested that a more diverse teaching population could play a role in reducing occupational stereotyping by all people, thus making it more acceptable for minority students to choose teaching or other influential occupations as potential careers. One Asian New Zealander, despite feeling that race-matched teaching would not confer any personal benefits, claimed he "would like to see [more minority teachers] just to show we can be teachers, because people generally think us incapable of teaching English students" (SKNZ Student 4).

\subsubsection{Increased Racial Tolerance}

All student groups suggested that a more ethnically diverse teaching population could increase racial tolerance: "It could make students more accepting and more considerate of people from other cultures" (ENZ Student 3). Some students indicated that racial intolerance and stereotyping in the education sector is not just the domain of students, however, and 
suggested that teachers can also contribute to making schools unfriendly environments for some minority students. Some suggested a domino-effect, speculating that increased numbers of minority teachers could lead to a culture that is more tolerant of diversity, and that in turn might encourage more minority students to consider teaching as a career: "Then if you do get an Asian teacher, no one's going to go, 'Oh, my God, he's Asian!', because it's just accepted"' (CNZ Student 2). However, while acknowledging that "ethnic understanding and tolerance is a must", one Anglo-European heritage parent added, "but New Zealand should be uniquely New Zealand - that's why we live here" (ENZ Parent 3).

\subsection{Training all Teachers to Work with Diversity}

Student participants in all groups discussed the qualities they valued in teachers and debated whether and how these were related to a teacher's race or ethnicity. Most concurred that quality teaching was more important than race-matched teaching, although what constituted quality teaching for the different groups was not clearly defined. This notion was particularly salient for the South Korean heritage student participants: "As long as you can acquire the knowledge you desire, it doesn't matter if the teacher is black, blue, orange, white, red, green, or purple" (SKNZ Student 1). One South Korean parent respondent echoed this opinion when he stated: "Good teachers are good teachers regardless of nationality or race" (SKNZ Parent 2). Again, however, the notion of what constituted a "good teacher" for this respondent was unclear.

Students in the Chinese and Anglo-European heritage groups stressed that all new teachers should receive training as part of their teacher education programmes to ensure they can work effectively with students from diverse cultural backgrounds. The Chinese New Zealand student group also highlighted the need for training for existing teachers "so they understand about different cultures, but don't just treat everyone from the same country the same" (CNZ Student 3).

\section{Discussion}

The intent of this study was to explore the perceived value of a teaching workforce that more closely aligns with the ethnic profile of the total New Zealand population. Sampling limitations and the methodology employed for the study dictate that readers must regard the study's findings as indicative only, and, as pointed out earlier, their transferability to other contexts must be carefully assessed. However, the complexities within the perceived outcomes for increased teacher diversity that emerged from the study warrant further discussion and investigation.

As in Gordon's (2000b) earlier research in the United States, the Asian-background respondents in this study largely dismissed the potential benefits that they identified for race-matched teaching. The perceived advantages of a same-race teacher were countered for most of the minority participants by the need for generation 1.5 students to improve their English ability and to "get into New Zealand society" (CNZ Parent 1).

In fact, a degree of race-matched teaching has been experienced by a growing portion of the New Zealand population for some time now, as the focus on Māori language revitalisation 
and indigenisation of the pedagogy have gained traction over the past two decades. Māori medium education is now available in many regions, either in stand-alone institutions or units within mainstream schools, and Māori teachers and students comprise the majority ethnicity in these bilingual and immersion units across all sectors. Teacher recruitment campaigns and scholarships targeting Māori candidates aim to increase the supply of teachers for such programmes, as well as to increase the representation of Māori teachers in all schools. The rationale for these campaigns includes the benefits that can ensue when a teacher shares the same language and background as minority students (TeachNZ, 2007).

Bilingual and immersion programmes are also available for Pasifika students at more than 30 schools within the New Zealand state education system, and the Ministry of Education reinforces the notion that race-matched teaching has merit in its Pasifika Education Plan: 2006-2010 (MOE, 2006b). This initiative is a part of a portfolio of Ministry of Education strategies to address the disproportionate representation of Māori and Pasifika students in educational underachievement statistics, and includes increasing the number of Pasifika teachers in the compulsory education sector as a key goal (Compulsory Education section, para. 4).

To date, no similar state funded programmes for ethnicity- or language-matched education exist for students from Asian or other ethnic backgrounds in New Zealand, and the results of this study indicate that such initiatives may not be welcomed or regarded as necessary by Chinese and South Korean heritage New Zealanders. Certainly, attempts at ethnic or language pairing for other groups of New Zealand students and teachers would be extremely controversial and would create impossible logistical and staffing challenges. Similarly, proportional representation of minority ethnicity staff in all New Zealand schools would be extremely challenging. Exact representation may not be necessary, though, for many of the potential positive outcomes posited by participants in this study to be realised.

Although Asian-ancestry parents and students in this study did not regard race-matched teaching as desirable, all groups perceived advantages in having a more ethnically representative teaching workforce and a teaching profession whose training prepared them to work effectively with students from diverse language and cultural backgrounds. This has important implications for teacher education programmes.

\subsection{Implications for Teacher Education}

\subsubsection{Attracting and Retaining Minority Students}

Achieving a more ethnically representative teaching workforce in countries with increasingly multiethnic populations requires that teacher education enrolments are more reflective of the ethnic composition of the wider population. This presents educational policy-makers and teacher education recruiters with a number of challenges.

Many minority students in Western countries do not make it sufficiently far along the educational pipe-line to be eligible for entry into initial teacher programmes, and proposed solutions (such as alternative entry pathways, pre-service courses designed specifically for indigenous students, and reserved places for minority students) raise further issues. However, 
many generation 1.5 students do achieve highly in their secondary education, but do not choose teaching as a career. Studies indicate that while salary and status are important considerations for many of these students, they are by no means the only factors deterring them from becoming teachers. Racism and other forms of discrimination, the fear of not being accepted, and encounters with mainstream teachers who are not prepared for diversity are among the many factors reported as deterrents by minority students in a number of Western contexts (Beynon et al., 1998; Gordon, 1994, 2000a; Howard, 2009). Some minority groups may also noticeably absent from national teacher recruitment campaigns and scholarship schemes. These factors need to be addressed in future initiatives aimed at attracting more minority students into teaching.

Once enrolled in pre-service programmes, minority students must be assured of an environment where their differing cultural voices and knowledges have are genuinely acknowledged, and where potential gaps in their awareness of majority culture practices in relation to education, in particular, are resolved in a structured and supportive way. By assuming that all participants have equal "access to the local, nationally grounded knowledge of education, schooling, teaching and learning that [is] the taken-for-granted focus of their teacher education programmes" (Han \& Singh, 2007, p. 9), many teacher education institutions unwittingly continue to privilege the majority culture students. Lack of familiarity with student-centred pedagogies can result in frustrating and unsuccessful practicum experiences for many minority culture students and this contributes to the early withdrawal of some students from initial teacher education programmes. It is important that effective interventions are available during early practicums to ensure minority students' encounters with differing classroom practices are positive and well supported. Provision for ongoing English language development throughout the teacher education period is also important if required.

\subsubsection{Preparing all Teachers for Diversity}

In recent research on effective learning and achievement, Hattie (2009) determined that of the many contributing factors the major source of variance that can make a difference to student achievement is the classroom teacher: "It is what teachers know, do and care about which is very powerful in this learning equation" (Hattie, 2002, p. 6). This places a great deal of responsibility on initial teacher education providers to ensure that all teachers who complete their training are prepared for the changing composition of their student cohorts. Programmes must not only foster a strong personal cultural awareness in prospective teachers, but also an ability to 'walk in the shoes' of their culturally and linguistically diverse students, and to acknowledge the heterogeneity of students from outwardly similar backgrounds. As Basil Bernstein famously stated: "If the culture of the teacher is to become part of the consciousness of the child, then the culture of the child must first be in the consciousness of the teacher" (1972, p. 149).

Ladson-Billings (1994) and Gay (2000) are prominent among researchers who stress the critical role of this type of awareness and caring, with Gay identifying it as "one of the major pillars of culturally responsive pedagogy for ethnically diverse students" (p. 45). Strategies 
within teacher education programmes which help to develop culturally responsive dispositions in pre-service teachers can also assist in minority trainee retention by creating more positive and inclusive learning environments (Kidd, Sánchez \& Thorp, 2008).

Pre-service training is not sufficient by itself, though, to prepare all teachers for increasingly multicultural classrooms. In-service professional development must also be provided to ensure the existing cohort of teachers is skilled in a pedagogy that provides for culturally inclusive and responsive classroom practices. Te Kōtahitanga is one project currently being trialled in New Zealand that is endeavouring to change mainstream secondary teachers' practices by means of an in-service professional development programme. The project aims to reduce the deficit positioning of Māori students by equipping experienced teachers with tools to acknowledge the cultural identities and experiences that Māori students bring to the classroom. The early success of Te Kōtahitanga (Bishop, Berryman, Cavanagh, \& Teddy, 2007) lends support to the thesis that appropriately trained majority-culture teachers can create learning environments with successful academic and affective outcomes for minority ethnicity students.

\subsection{Further Research}

Further studies with larger groups from a number of ethnic backgrounds will allow for the influence of variables other than ethnicity to be considered in relation to the issues explored in this study, and for the degree of heterogeneity within and between the different ethnic groups to be more meaningfully explored. Further research is also required to provide empirical evidence for the hypothesised effects of teacher-student ethnicities on minority and dominant culture students, and to provide a better understanding of why and how these relationships make a difference. Ongoing research into the effectiveness of specific teacher education strategies for working with diverse groups of learners will contribute to preparing all teachers for successful engagement in increasingly multiethnic classrooms.

\section{Conclusion}

In 1907, the American historian Henry Adams wrote, "A teacher affects eternity; he can never tell where his influence stops" (1907/1918, p. 300). A century later, the Anglo-European and Asian New Zealanders who participated in the study that is the focus of this article have provided insights into some of the legacies that they perceive an ethnically diverse teaching profession could bestow on students and their wider communities. While race-matched teaching was not regarded as desirable by most of the respondents, the possibility of a more just and tolerant society resulting from a more diverse teaching population was posited by minority and majority culture students alike. In the words of one participant: "It would be better for everyone" (ENZ Student 3).

International research supports Futrell (1999) when he states:

It is essential for all teachers to have the knowledge, skills, and training to successfully teach diverse student populations. But it is equally important for all students to have the opportunity to be taught by teachers who reflect their diversity. (p. 30) 
Teacher education programmes are a critical link in providing such an ethnically diverse and culturally responsive teaching workforce to help ensure that future students of all backgrounds have a genuinely equitable educational environment, not only in New Zealand but in other countries undergoing similar demographic transformation.

\section{References}

"Pacific Pearls". (2007, May 25). The University of Auckland News, 37(9), p. 5.

Adams, H. (1918). The education of Henry Adams. Boston: Houghton Mifflin/The Riverside Press. (Original work published 1907).

Alton-Lee, A. (2003). Quality teaching for diverse students in schooling: Best evidence synthesis. Wellington, New Zealand: Ministry of Education.

Armstrong, D.G., \& Savage, T.V. (2002). Teaching in the secondary school: An introduction (5th ed.). Upper Saddle River, NJ: Merrill/Prentice Hall.

Barbieri, S.M. (1998, August 9). Reaching for teachers. St Paul Pioneer Press, p. B1.

Bennett, C.I. (2003). Comprehensive multicultural education: Theory and practice (5th ed.). Boston, MA: Allyn and Bacon.

Bernstein, B. (1972). A critique of the concept of compensatory education. In C. Cazden, V. John \& D. Hymes (Eds.), Functions of language in the classroom (pp. 135-151). New York: Teachers College Press.

Beynon, J., Toohey, K., \& Kishor, N. (1998). Do visible minority students of Chinese and East Asian ancestry want teaching as a career? Perceptions of some secondary school students in Vancouver, B.C. Canadian Ethnic Studies, 30(2), 50-72.

Bishop, R., Berryman, M., Cavanagh, T., \& Teddy, L. (2007). Te Kōtahitanga phase 3 whānaungatanga: Establishing a culturally responsive pedagogy of relations in mainstream secondary classrooms. Wellington, New Zealand: Ministry of Education. Retrieved April 12, 2010. [Online] Available: http://www.educationcounts.govt.nz/_data/assets/pdf_file/0004/ 9922/Te_Kotahitanga_Phase3.pdf.

Bishop, R., Berryman, M., Powell, A., \& Teddy, L. (2007). Te Kōtahitanga: Improving the educational achievement of Māori students in mainstream education. Phase 2: Towards a whole school approach. Wellington, New Zealand: Ministry of Education. Retrieved April 12, 2010. [Online] Available: http://www.educationcounts.govt.nz/_data/assets/pdf_file/ 0009/9909/TeKotahitanga-Phase2.pdf.

Bogdan, R., \& Biklen, S. (1992). Qualitative research for education: An introduction to theory and methods (2nd ed.). Boston, MA: Allyn and Bacon.

Brosnan, M. (2002). Hiring and retaining teachers of color: The why and how of it. Norwell, MA: AISNE, Association of Independent Schools in New England. 
Burns, R.B. (2000). Introduction to research methods (4th ed.). Frenchs Forest, NSW: Pearson Education.

Carnegie Taskforce on Teaching as a Profession. (1986). A nation prepared: Teachers for the 21st century. New York: Carnegie Forum on Education and the Economy.

Casteel, C.A. (1998). Teacher-student interactions and race in integrated classrooms. Journal of Educational Research, 92(2), 115-120.

Chaika, G. (2005). Recruiting and retaining minority teachers: Programs that work. Retrieved April 12, 2010. [Online] Available: http://www.educationworld.com/a_admin/ admin/ admin213.shtml.

Chang, S., Morris, C., \& Vokes, R. (2006). Korean migrant families in Christchurch: Expectations and experiences. Wellington, New Zealand: Families Commission.

Chinn, P.C., \& Wong, G.Y. (1992). Recruiting and retaining Asian/Pacific American teachers. In M.E. Dilworth (Ed.), Diversity in teacher education: New expectations (pp. 112-133). San Francisco: American Association of Colleges of Teacher Education/Jossey-Bass.

Committee for the Review of Teaching and Teacher Education. (2003). Australia's teachers: Australia's future. Advancing innovation, science, technology and mathematics. Agenda for action. Canberra, Australia: Department of Education, Science and Training.

Davidson, C., \& Tolich, M. (2003). Social Science research in New Zealand (2nd ed.). Auckland: Pearson.

Dee, T.S. (2001). Teachers, race and student achievement in a randomized experiment. NBER Working Paper Series (ERIC Document Reproduction Service Number ED464172).

Dee, T.S. (2005). A teacher like me: Does race, ethnicity or gender matter? American Economic Review, 95(2), 158-165.

Ehrenberg, R.G., Goldhaber, D.D., \& Brewer, D.J. (1995). Do teachers' race, gender, and ethnicity matter? Evidence from the National Educational Longitudinal Study of 1998. Industrial and Labor Relations Review, 48(3), 547-561.

Ferguson, R. (1998). Teachers' perceptions and expectations and the Black-White test score gap. In C. Jencks \& M. Phillips (Eds.), The Black-White test score gap (pp. 273-317). Washington DC: Brookings Institution.

Ford, D.Y., Grantham, T.C., \& Harris, J.J. (1997). The recruitment and retention of minority teachers in gifted education. Roeper Review, 19(4), 213-220. (ERIC Document Reproduction Service Number EJ550590).

Futrell, M.H. (1999). Recruiting minority teachers. Educational Leadership, 56(8), 30-33.

Gagliardi, R. (1995). Studies in comparative education: Teacher training and multiculturalism. Paris: International Bureau of Education, UNESCO. 
Gay, G. (2000). Culturally responsive teaching: Theory, practice and research. New York: Teachers College Press.

Genzuk, M. (1997). Diversifying the teaching force: Preparing paraeducators as teachers. (ERIC Document Reproduction Service Number ED406362).

Gordon, J.A. (1994). Why students of color are not entering teaching: Reflections from minority teachers. Journal of Teacher Education, 45(5), 346-353.

Gordon, J.A. (2000a). Asian American resistance to selecting teaching as a career: The power of community and tradition. Teachers College Record, 102(1), 173-196.

Gordon, J.A. (2000b). The color of teaching. London: RoutledgeFalmer.

Gordon, J.A. (2002). The color of teaching revisited. Multicultural Perspectives, 4(2), 3-7.

Gordon, L., Mutch, C., Howard, J., Heazlewood, L., Coleman, S., \& Hendren, J. (2006). Final report for the evaluation of the Code of Practice for the Pastoral Care of International Students. Wellington, New Zealand: Ministry of Education.

Gursky, D. (2002). Recruiting minority teachers. Education Digest, 67(8), 28-35.

Han, J., \& Singh, M. (2007). Getting world English speaking student teachers to the Top of the Class: Making hope for ethno-cultural diversity in teacher education robust. Asia-Pacific Journal of Teacher Education, 35(3), 291-309.

Hartsuyker, L. (2007). Top of the class: Report on the inquiry into teacher education. Canberra, Australia: The Parliament of the Commonwealth of Australia.

Hattie, J. (2002) What are the attributes of an excellent teacher? In New Zealand Council for Educational Research (Ed.), Teachers make a difference. What is the research evidence? Wellington, New Zealand: New Zealand Council for Educational Research.

Hattie, J. (2009). Visible learning: A synthesis of over 800 meta-analyses relating to achievement. New York: Routledge.

Howard, J. (2009). Pride and prejudice ... and other barriers to teaching for Asian New Zealanders. Asia Pacific Journal of Education, 29(2), 143-157.

Kane, P.R., \& Orsini, A.J. (Eds.). (2003). The colors of excellence: Hiring and keeping teachers of color in independent schools. New York: Teachers College Press.

Kennedy, M.M. (1991). Policy issues in teacher education. Phi Delta Kappan, 72(9), 659-665.

Kidd, J.K., Sánchez, S.Y., \& Thorp, E.K. (2008). Defining moments: Developing culturally responsive dispositions and teaching practices in early childhood preservice teachers. Teaching and Teacher Education, 24(2), 316-329.

Krueger, R.A., \& Casey, M.A. (2000). Focus groups: A practical guide for applied research (3rd ed.). Thousand Oaks, CA: Sage. 
Ladson-Billings, G. (1994). The dreamkeepers: Successful teachers for African-American children. San Francisco: Jossey-Bass.

LaPlante, M.P., \& Carlson, D. (1996). Disability in the United States: Prevalence and causes, 1992. (ERIC Document Reproduction Service Number ED400635).

Lee, C. (1991). Achieving diversity: Issues in the recruitment and retention of underrepresented racial/ethnic students in higher education. Alexandria, VA: National Association of College Admission Counselors.

Merriam, S.B. (1998). Qualitative research and case study applications in education. San Francisco, CA: Jossey-Bass.

Milem, J.F. (2003). The educational benefits of diversity: Evidence from multiple sectors. In M. Chang, D. Witt, J. Jones, \& K. Hakuta (Eds.), Compelling interest: Examining the evidence on racial dynamics in higher education (pp. 126-169). Palo Alto, CA: Stanford University Press.

Miller, C., \& Endo, H. (2005). Journey to becoming a teacher: The experiences of a student of color. Multicultural Education, 13(1), 2-9.

Ministry of Education (2006b). Pasifika education plan: 2006-2010. Wellington, New Zealand: Ministry of Education.

Ministry of Education (2007). School roll summary report: July 2007. Wellington, New Zealand: Ministry of Education. Retrieved April 12, 2010. [Online] Available: http://www.educationcounts.govt.nz/publications/series/2259/july_school_roll_returns/school _roll_summary_report_july_2007.

Ministry of Education. (2005). Report on the findings of the 2004 teacher census. Wellington, New Zealand: Ministry of Education. Retrieved April 12, 2010. [Online] Available: http://www.educationcounts.govt.nz/publications/schooling/teacher_census.

Ministry of Education. (2006a). Beginning teachers 2000-2004: Characteristics, employment trends, qualifications and subjects. Wellington, New Zealand: Ministry of Education. Retrieved April 12, 2010. [Online] Available: http://www.educationcounts.govt.nz/_data/ assets/pdf_file/0004/6367/beginning-teachers-2004.pdf .

Neal, L.I., McCray, A.D., Webb-Johnson, G., \& Bridges, S.T. (2003). The effects of African-American movement styles on teachers' perceptions and reactions. Journal of Special Education, 37(1), 49-57.

Nieto, S. (1999). What does it mean to affirm diversity? School Administrator, 56(5), 32-34.

Peng, S.S., \& Wright, D. (1994). Explanation of academic achievement of Asian American students. Journal of Educational Research, 87(6), 346-352.

Rasmussen, K. (1999). Preparing two million: How districts and states attract and retain teachers. Education Update, 41(1). Retrieved April 12, 2010. [Online] Available: http://www.ascd.org/publications/newsletters/education_update/jan99/vol41/num01/Preparin g_Two_Million.aspx. 
Rong, X.L., \& Preissle, J. (1997). The continuing decline in Asian American teachers. American Educational Research Journal, 34(2), 267-293.

Sianjina, R.R., Cage, B., \& Allen, V.A. (1996). African-Americans' participation in teaching education programs. The Educational Forum, 61(1), 30-33.

Statistics New Zealand. (2007). 2006 Census of population and dwellings: Quickstats about culture and identity. Retrieved April 12, 2010. [Online] Available: http://search.stats.govt.nz/search?w=2006\%20census.

Statistics New Zealand. (2010). Demographic trends: 2009. Retrieved April 12, 2010. [Online] Available: http://www.stats.govt.nz/publications/populationstatistics/demographictrends-2009aspx.

Stokes, S.M. (1999). A partnership for creating a multicultural teaching force: A model for the present. Multicultural Education, 7(1), 8-12.

$\mathrm{Su}, \mathrm{Z}$. (1996). Why teach: Profiles and entry perspectives of minority students as becoming teachers. Journal of Research and Development in Education, 29(3), 117-133.

TeachNZ. (2007). Why more Māori teachers? Wellington, New Zealand: Author. Retrieved April 12, 2010. [Online] Available: www.teachnz.govt.nz/thinking-of-becoming-a-teacher/ maori/why-more-maori-teachers.

Telford, M., \& Caygill, R. (2007). How ready are our 15-year-olds for tomorrow's schools? Wellington, New Zealand: Ministry of Education.

Torres, J., Santos, J., Peck, N.L., \& Cortes, L. (2004). Minority teacher recruitment, development, and retention. Providence, RI: Brown University, Education Alliance.

Tyler, N.C., Yzquierdo, Z., Lopez-Reyna, N., \& Flippin, S.S. (2004). Cultural and linguistic diversity in special education: A critical overview. Journal of Special Education, 38(1), 22-38.

Vaughn, S., Schumm, J., \& Sinagub, J. (1996). Focus group interviews in education and psychology. Thousand Oaks, CA: Sage.

Vegas, E., Murnane, R.J., \& Willett, J.B. (2001). From high school to teaching: Many steps, who makes it? Teachers College Record, 103(3), 427-449.

Villegas, A.M., \& Clewell, B.C. (1998). Increasing the number of teachers of color for urban schools. Education and Urban Society, 31(1), 42-61.

\section{Notes}

Note 1. Researchers use different terms to refer to racially and ethnically diverse groups. This paper uses the term "minority" to refer to all immigrant and indigenous ethnic groups in New Zealand, individually or collectively, that are not of Anglo-European ancestry. This is not intended to deny the heterogeneity inherent within and between any of these diverse groups, nor to deny the contested and problematic nature of the term. The possibility of multi-ethnic identification is also acknowledged. When referring to or quoting from other studies, the 


\section{Macrothink

terms used in those studies are retained.

\section{Glossary}

Decile: Decile is the term used in New Zealand to indicate the proportion of students in a school that are drawn from low socio-economic communities. A Decile 1 school is in the $10 \%$ of schools with the greatest proportion of students from low socio-economic communities. A Decile 10 school is in the $10 \%$ of schools with the smallest proportion of students from low socio-economic communities.

Generation 1.5: This term refers to people who immigrate as young children or teens, thus sharing characteristics and experiences of both first generation and second generation migrants. Generation $1.5 \mathrm{ers}$ are characteristically young, foreign-born and often partially educated in their country of origin. While the term is subject to some ambiguity, it is intended to signal the 'cultural in-betweenness' of this group and indicates that these students are still in the formative stages of acculturation and identity development.

Māori: This is the generic name used for those people who self-identify as descendants of the indigenous people of New Zealand.

Pasifika: This is the generic name used in New Zealand for people of Pacific Islands origin. 